\title{
RE/SIDIR Y RE/SISTIR. Un ensayo sobre mis topofilias
}

\author{
RE / SIDE AND RE / SIST. An essay on my topophilias
}

\author{
Giselda E. Hernandez Ramírez \\ Departamento de Antropología \\ Universidad de las Artes de Cuba, Cuba. \\ giseldah41@gmail.com
}

Recibido 06/02/2018

Aceptado 24/05/2018
Revisado 20/04/2018

Publicado 01/07/2018

\section{Resumen}

Soy una migrante y como tal he sufrido pérdidas de mi capital social y cultural, no obstante, he desarrollado una relación con la corresidencia donde se halla mi casa, mi lugar. Vivo en La Lisa un barrio periférico de la ciudad de la Habana, Cuba, un lugar apartado y apuntalado de la geocultura capitalina, un municipio que ha creado su propio mundo sonoro contrapuntístico, donde se entretejen los cantos y toques de los negros cuando hacen sus fiestas de santos o simplemente se relajan en un fluido guaguancó, con el más subterráneo reguetón facilitado por un músico no reconocido a los choferes

\section{Abstract}

As a migrant, I have lost some parts of my social and cultural capital, however, I have developed a relationship with the co-residence, with the place where my house is. I live in La Lisa, a peripheral municipality of Havana City, in Cuba, a distant place of the downtown full of braced buildings. This neighborhood has created its own sound world with amazing counterpoints. There are a mixture among the black people's music (when they do their saints parties or during the relaxing guaguanco dance), the underground reguetton (these songs are given to the Almendrón ${ }^{1}$ driver by an unknown

1.- The Almendrón is a type of car very old which is used in Cuba yet. They are compared with a big almond due to its form, that's why its name./ El Almendrón es un tipo de gorra muy antigua que todavía se usa en Cuba. Se los compara con una gran almendra por su forma, por eso es su nombre.

Para citar este artículo

Hernández Ramírez, Giselda E. (2018). Re/sidir y re/sistir. Un ensayo sobre mis topofilias. Tercio Creciente, 14, págs. $49-64$. https://dx.doi.org/10.17561/rtc.n14.2 
de los flamantes Almendrones -coches de alquiler-, con los cantos de alabanzas de los protestantes que proliferan en mi barrio. Sí, mi barrio ya lo hago mío aunque no cejo en este ir y venir de un lado a otro al margen de todo, en las intermediaciones, mi barrio canta, baila y llora porque ha desarrollado una gran resistencia cultural. El barrio como mi cuerpo que se resiste a envejecer, lucha y resiste los embates del tiempo. Este ensayo visual es el resultado de una deriva por Versalles el barrio donde habito, resido y resisto. musician) and the songs belonged to the protestant religion. Yes, my neighborhood, which is mine although I cannot stop going and coming back, always in the middle of the way. My neighborhood sings, dances, cries, because it has developed a huge cultural resistance. My neighborhood, as my body, resists aging, fights and resists the time. This visual essay is the result of a drift around Versalles, the neighborhood where I live, reside and resist.

Palabras clave / Keywords

Migrante, corresidencia, deriva.

Migrant, co-residence, derive.

Para citar este artículo

Hernández Ramírez, Giselda E. (2018). Re/sidir y re/sistir. Un ensayo sobre mis topofilias. Tercio Creciente, 14, págs. 49-64.

https://dx.doi.org/10.17561/rtc.n14.2 


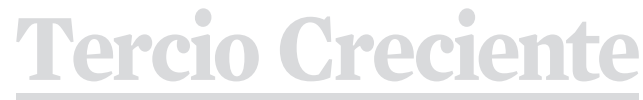

ISSN: 2340-9096

DOI: https://dx.doi.org/10.17561/rtc.n14.2
Revista de Estudios en Sociedad, Artes y Gestión Cultural

www.terciocreciente.com

http://revistaselectronicas.ujaen.es/index.php/RTC
Número 14

Julio 2018

Investigación ensayo visual

\section{Introducción}

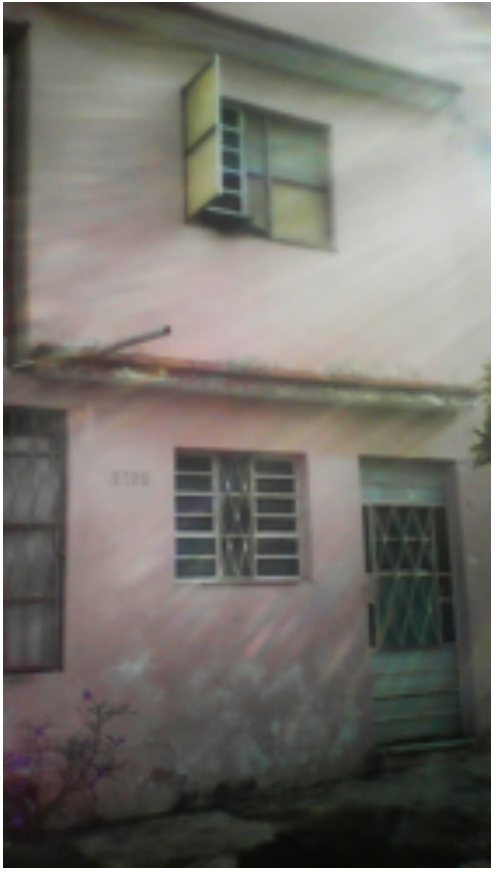

Mis ojos

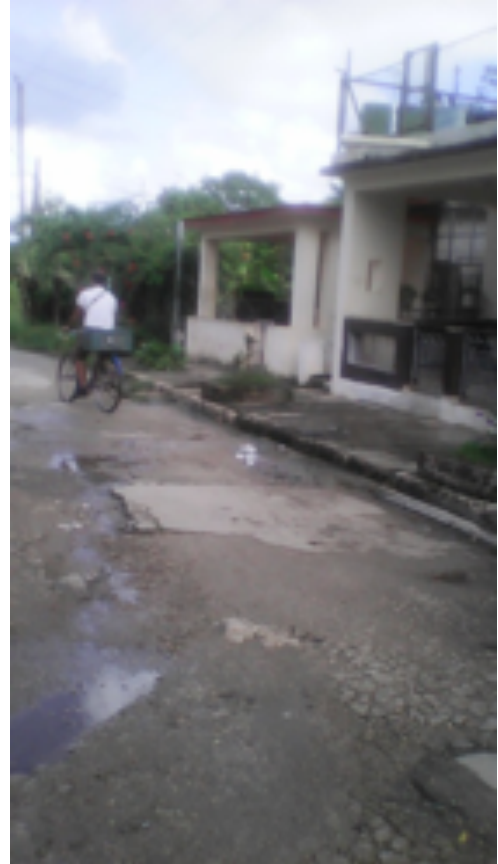

Mis venas agujeradas por los años 


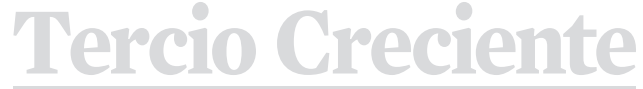

ISSN: 2340-9096

DOI: https://dx.doi.org/10.17561/rtc.n14.2
Revista de Estudios en Sociedad,

Artes y Gestión Cultural

www.terciocreciente.com

http://revistaselectronicas.ujaen.es/index.php/RTC
Número 14

Julio 2018

Investigación ensayo visual
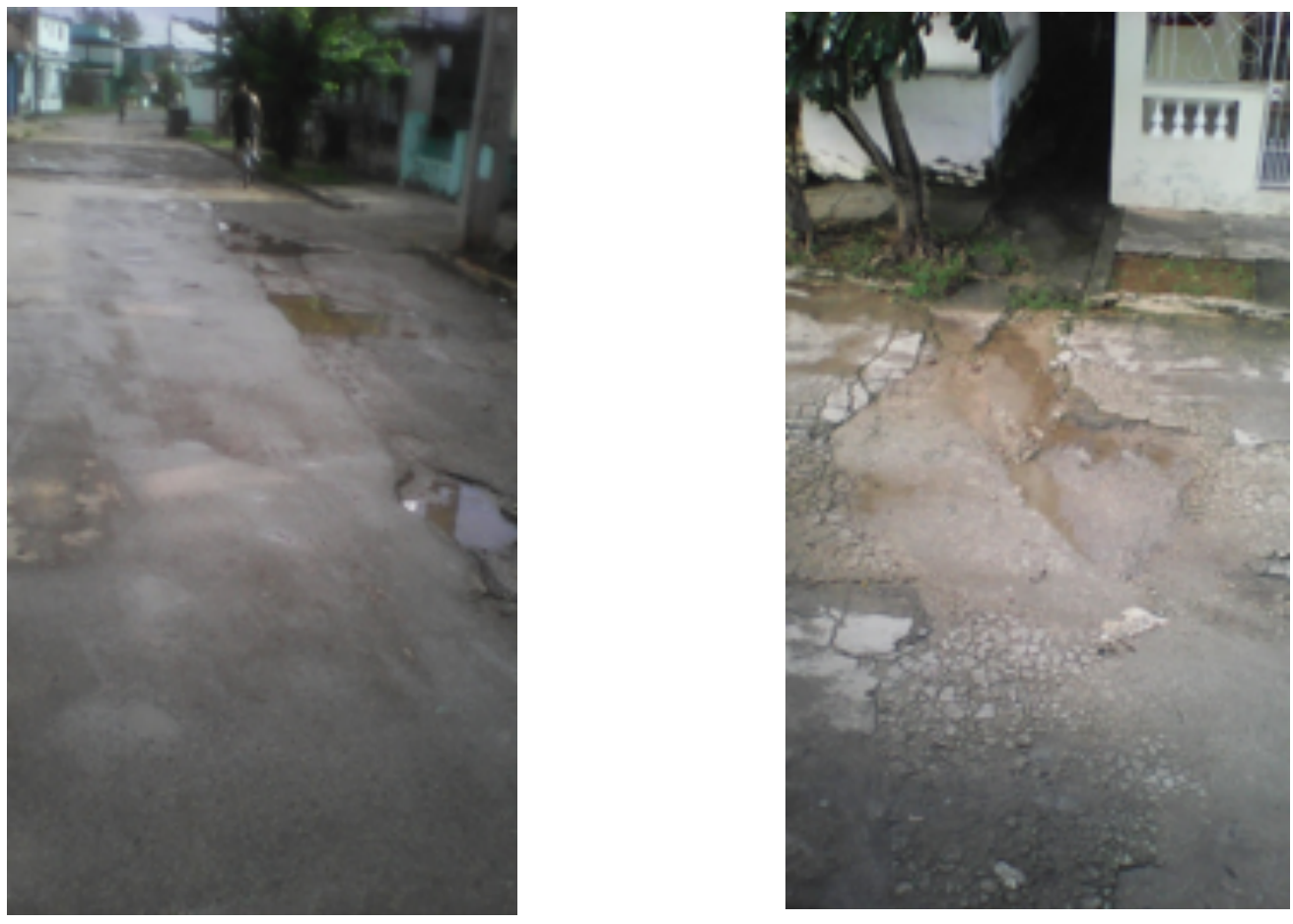

Los surcos de mi piel morena. 


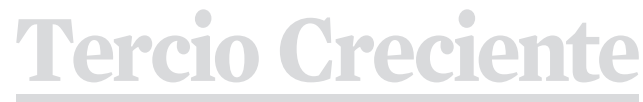

ISSN: 2340-9096

DOI: https://dx.doi.org/10.17561/rtc.n14.2
Revista de Estudios en Sociedad Artes y Gestión Cultural

www.terciocreciente.com

http://revistaselectronicas.ujaen.es/index.php/RTC
Número 14

Julio 2018

Investigación ensayo visual

La felicidad de algunos/nas. La búsqueda.
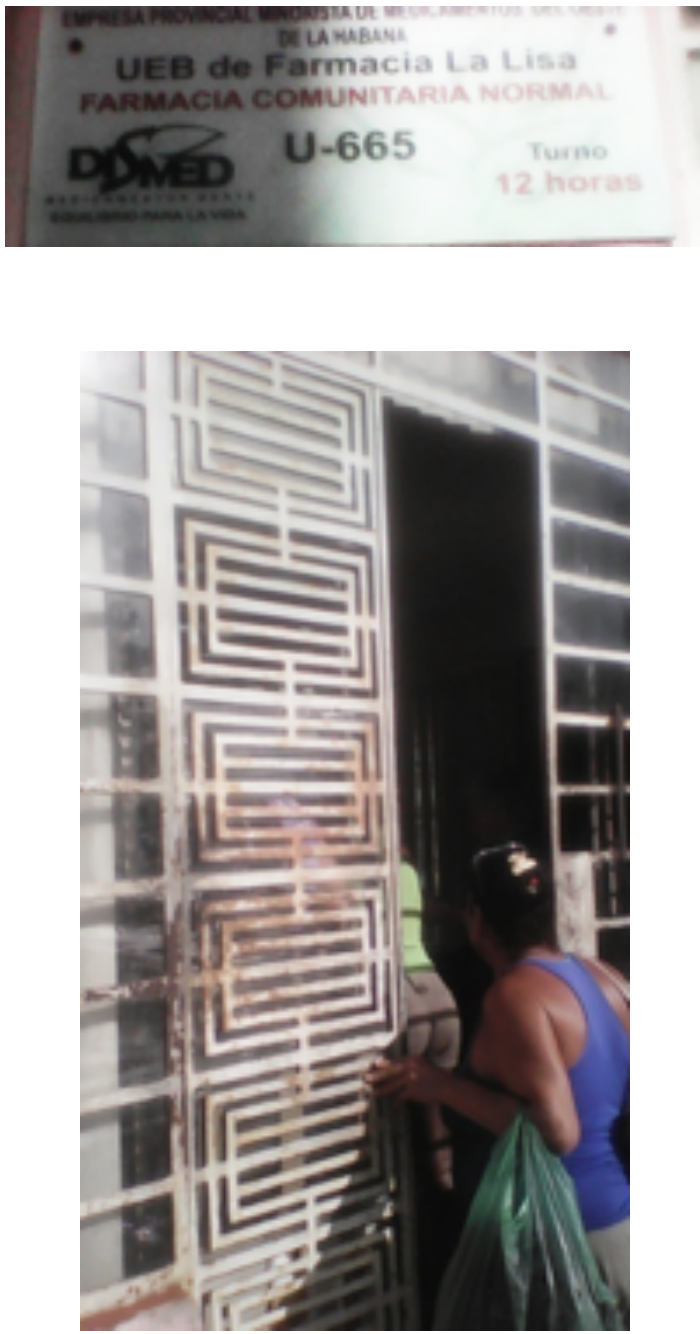


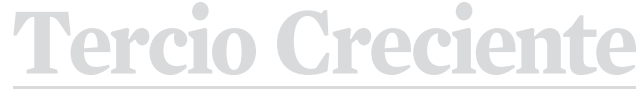

ISSN: 2340-9096

DOI: https://dx.doi.org/10.17561/rtc.n14.2
Revista de Estudios en Sociedad,

Artes y Gestión Cultural

www.terciocreciente.com

http://revistaselectronicas.ujaen.es/index.php/RTC
Número 14

Julio 2018

Investigación ensayo visual
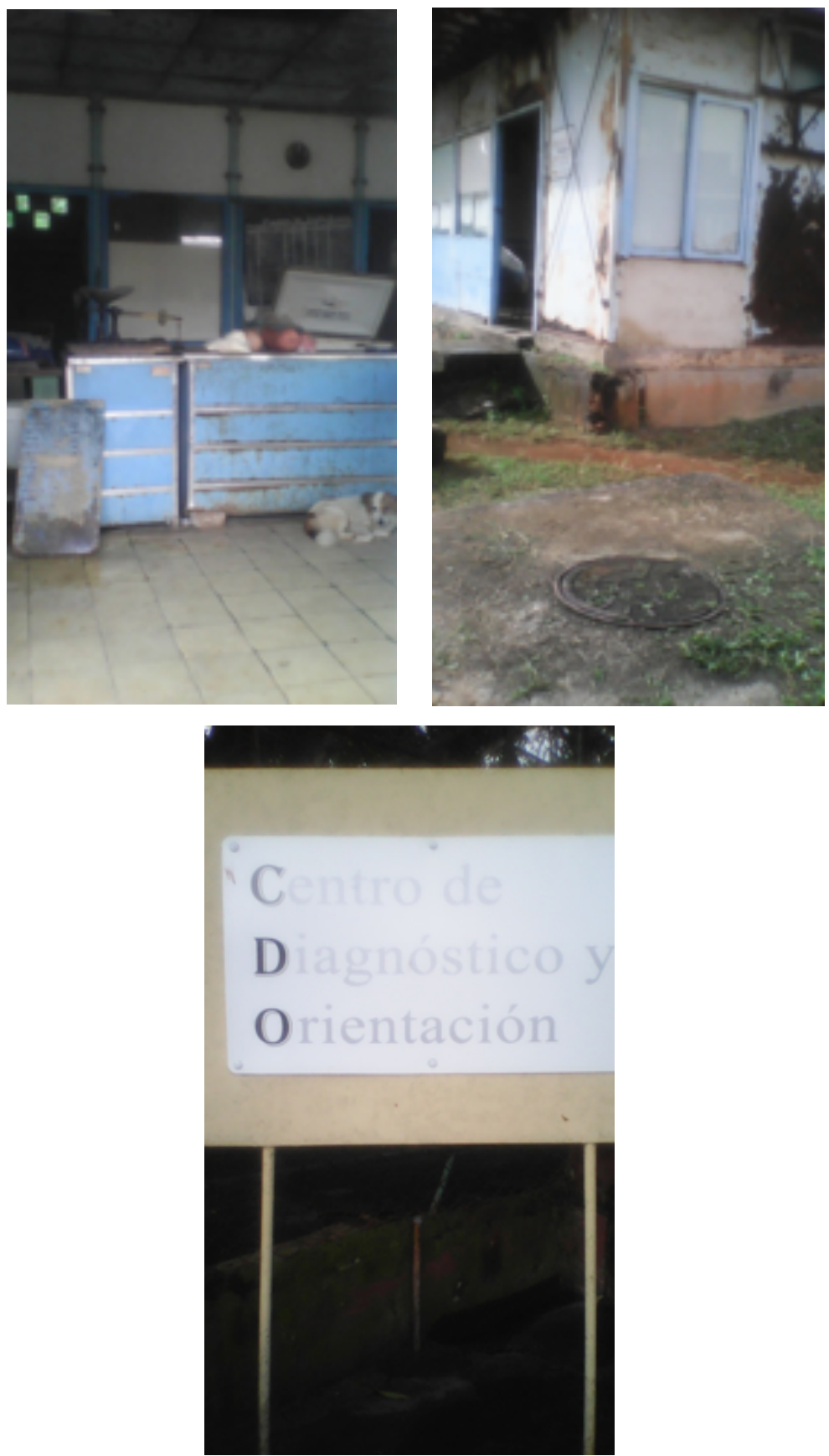


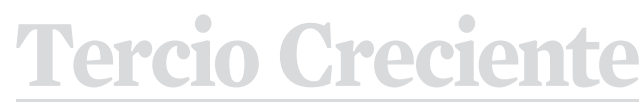

ISSN: 2340-9096

DOI: https://dx.doi.org/10.17561/rtc.n14.2
Revista de Estudios en Sociedad Artes y Gestión Cultural

www.terciocreciente.com

http://revistaselectronicas.ujaen.es/index.php/RTC
Número 14

Julio 2018

Investigación ensayo visual

Sin maquillaje
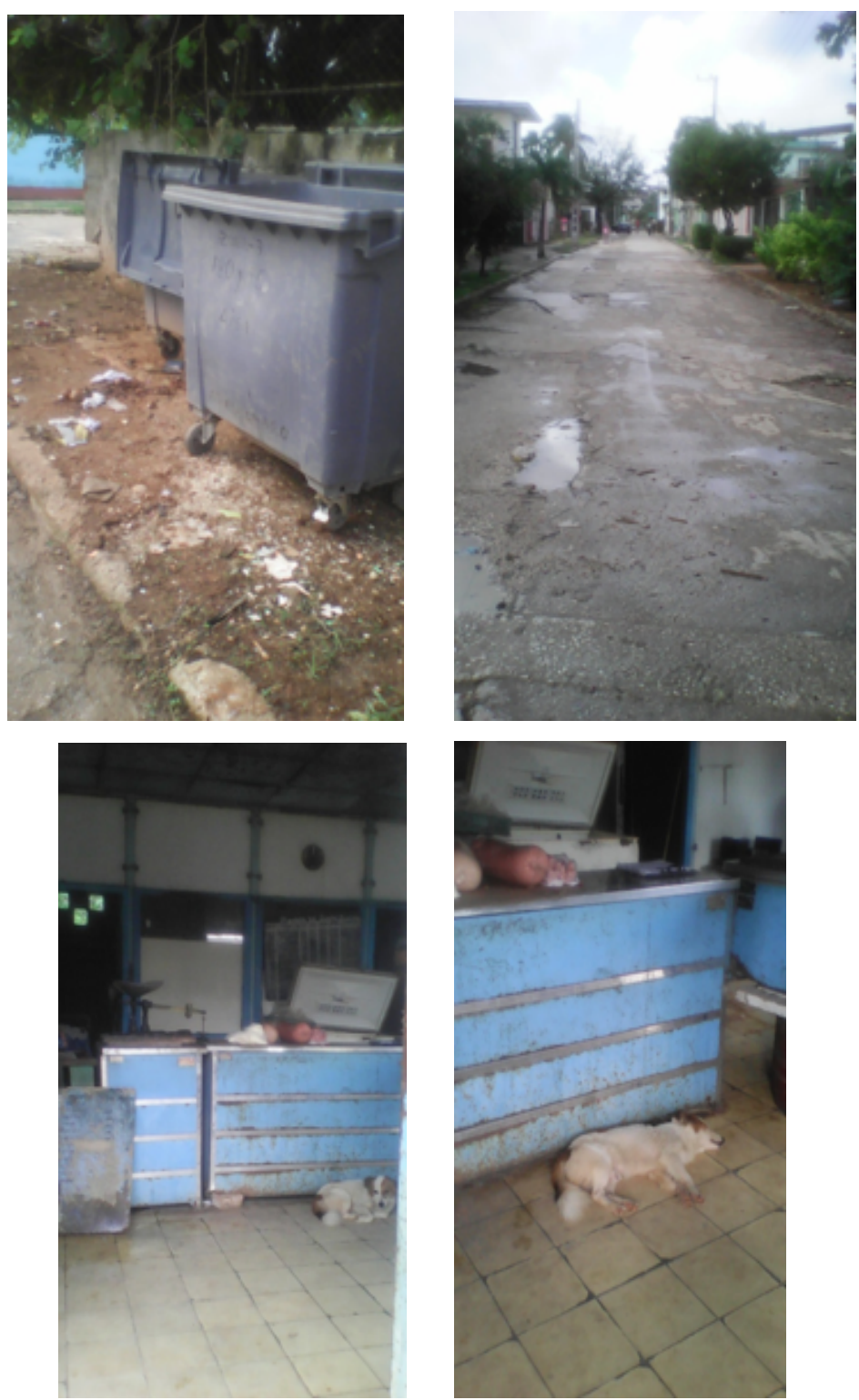
Tercio Creciente

ISSN: 2340-9096

DOI: https://dx.doi.org/10.17561/rtc.n14.2
Revista de Estudios en Sociedad,

Artes y Gestión Cultural

www.terciocreciente.com

http://revistaselectronicas.ujaen.es/index.php/RTC
Número 14

Julio 2018

Investigación ensayo visual

Mis miedos
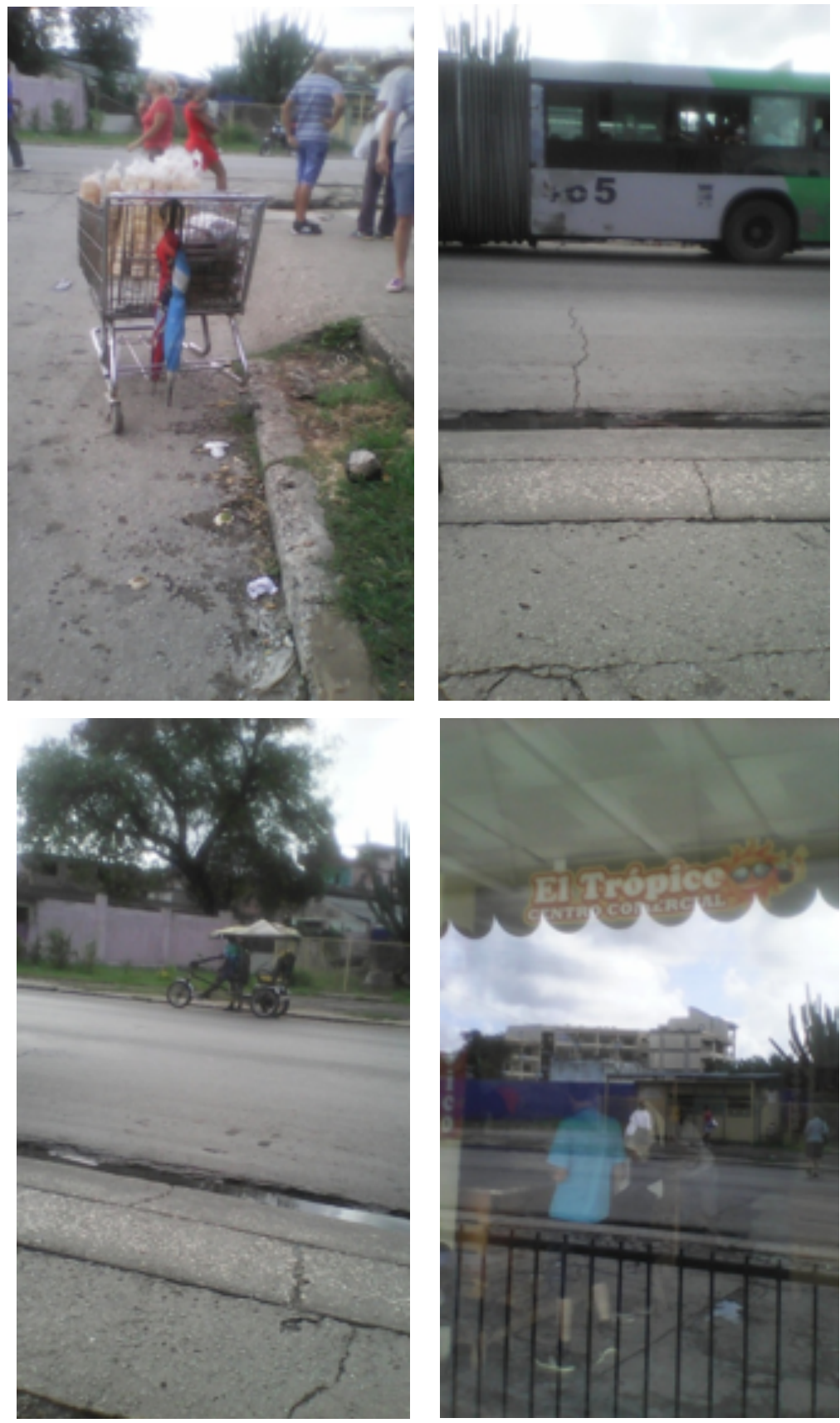


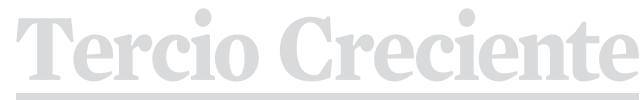

ISSN: 2340-9096

DOI: https://dx.doi.org/10.17561/rtc.n14.2
Revista de Estudios en Sociedad Artes y Gestión Cultural

www.terciocreciente.com

http://revistaselectronicas.ujaen.es/index.php/RTC
Número 14

Julio 2018

Investigación ensayo visual

Dios bendiga tus piernas
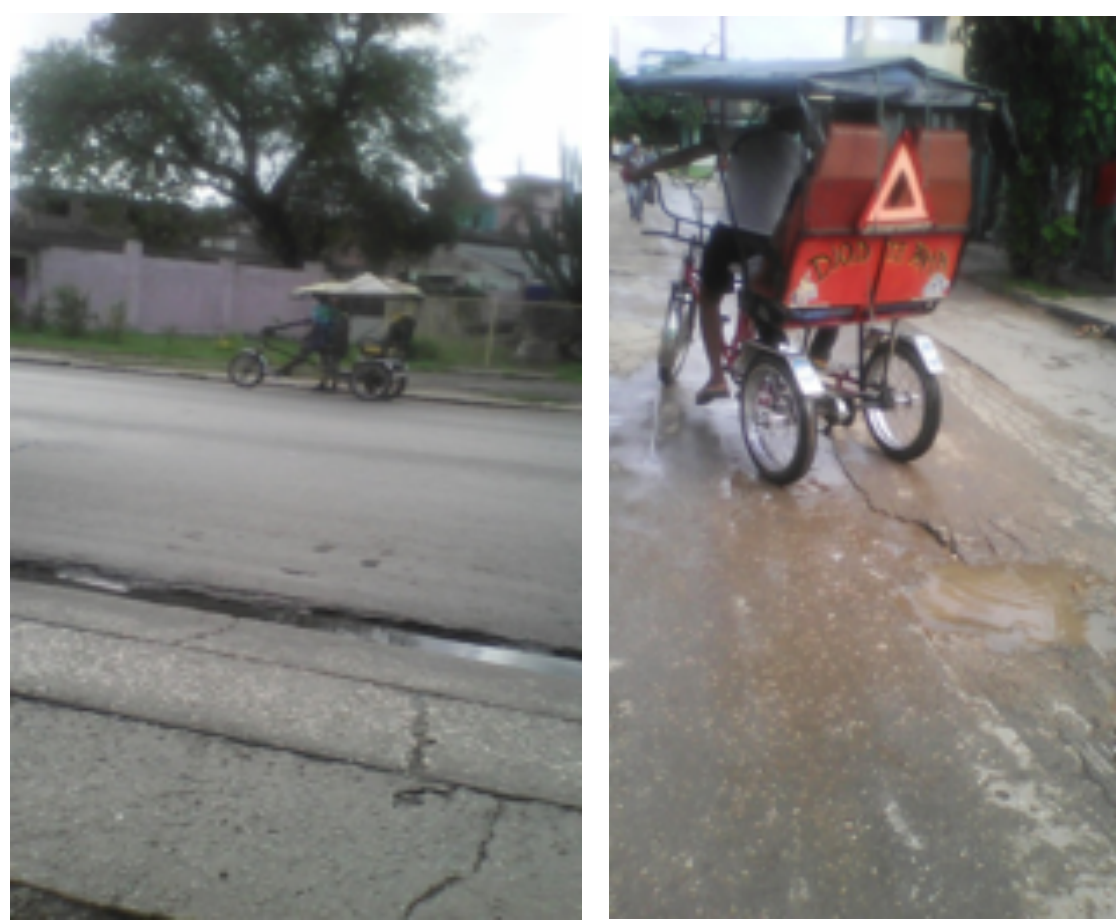
Tercio Creciente

ISSN: 2340-9096

DOI: https://dx.doi.org/10.17561/rtc.n14.2
Revista de Estudios en Sociedad,

Artes y Gestión Cultural

www.terciocreciente.com

http://revistaselectronicas.ujaen.es/index.php/RTC
Número 14

Julio 2018

Investigación ensayo visual

Asuntos de familia
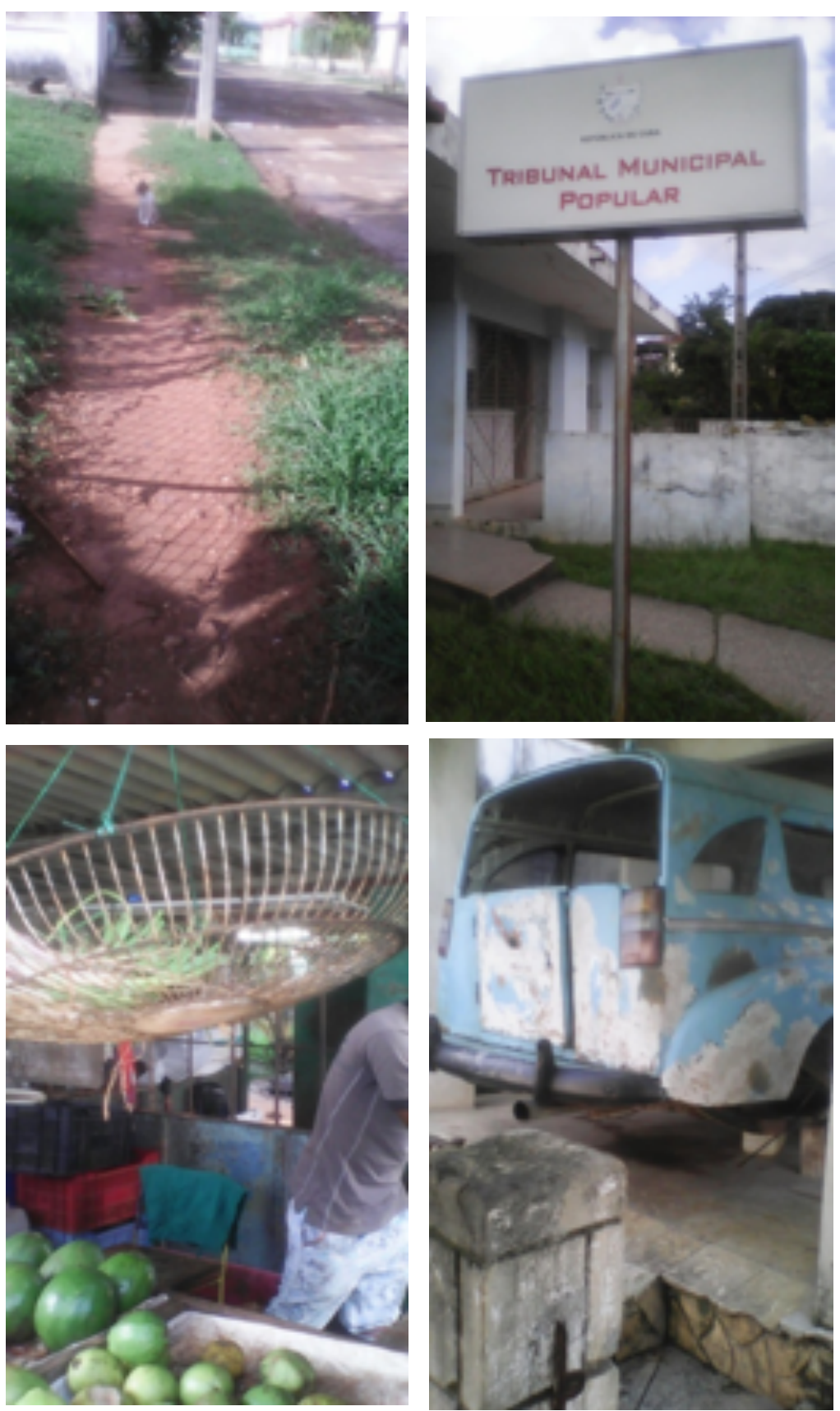
Tercio Creciente

ISSN: 2340-9096

DOI: https://dx.doi.org/10.17561/rtc.n14.2
Revista de Estudios en Sociedad Artes y Gestión Cultural

www.terciocreciente.com

http://revistaselectronicas.ujaen.es/index.php/RTC
Número 14

Julio 2018

Investigación ensayo visual
59

\section{Presa por mi estómago}
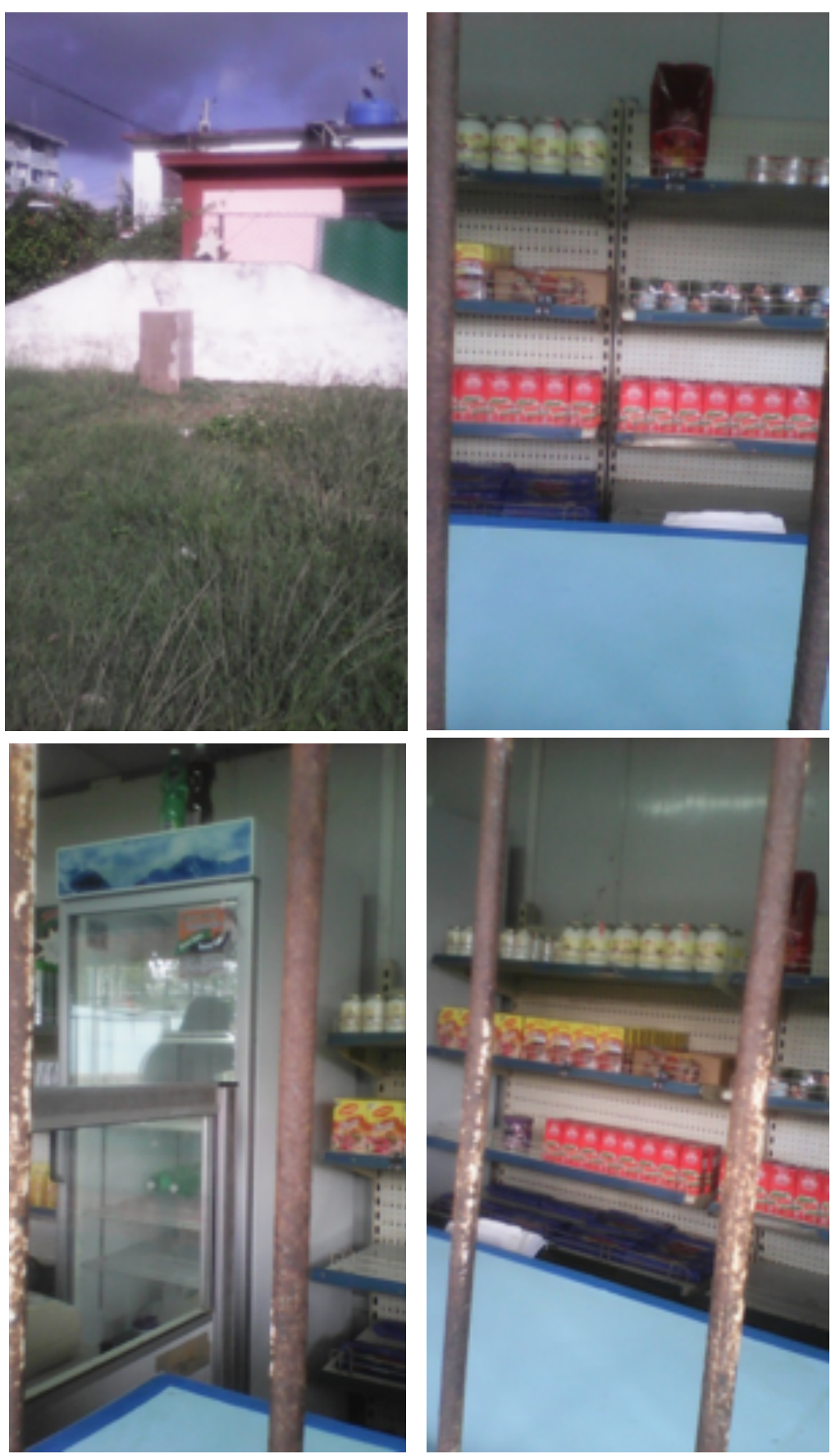


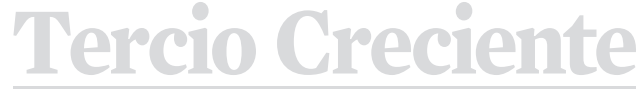

ISSN: 2340-9096

DOI: https://dx.doi.org/10.17561/rtc.n14.2
Revista de Estudios en Sociedad,

Artes y Gestión Cultural

www.terciocreciente.com

http://revistaselectronicas.ujaen.es/index.php/RTC
Número 14

Julio 2018

Investigación ensayo visual

Recolección, de vuelta a mis ancestros

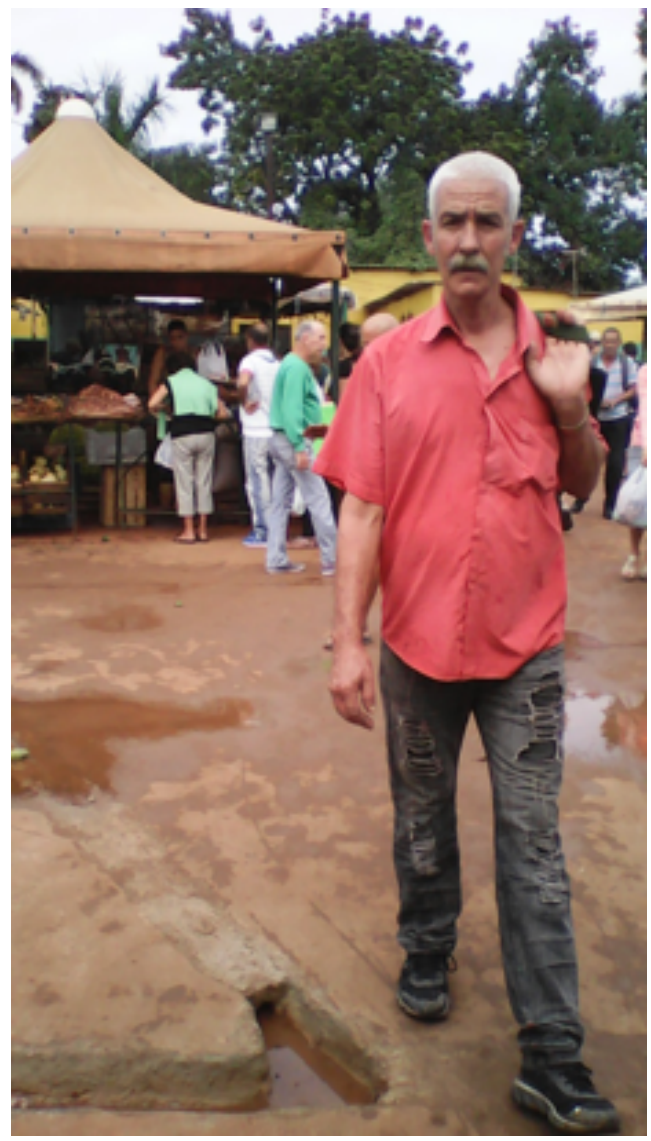


ISSN: 2340-9096

DOI: https://dx.doi.org/10.17561/rtc.n14.2
Revista de Estudios en Sociedad Artes y Gestión Cultural

www.terciocreciente.com

http://revistaselectronicas.ujaen.es/index.php/RTC
Número 14

Julio 2018

Investigación ensayo visual
61
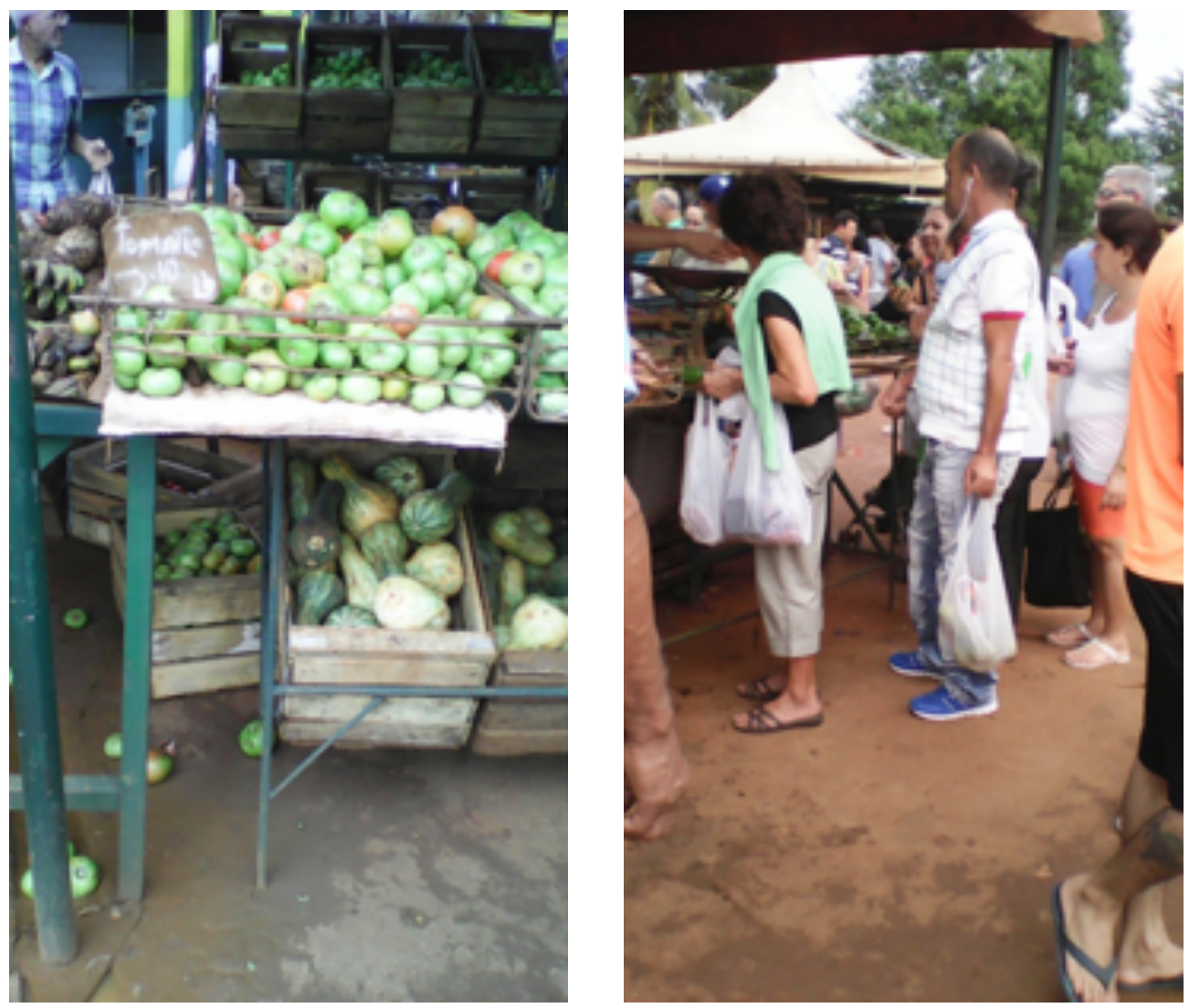


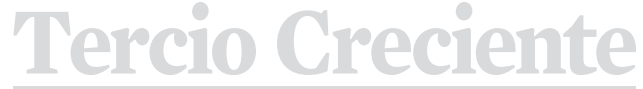

ISSN: 2340-9096

DOI: https://dx.doi.org/10.17561/rtc.n14.2
Revista de Estudios en Sociedad,

Artes y Gestión Cultural

www.terciocreciente.com

http://revistaselectronicas.ujaen.es/index.php/RTC
Número 14

Julio 2018

Investigación ensayo visual

¿Nos comunicamos?
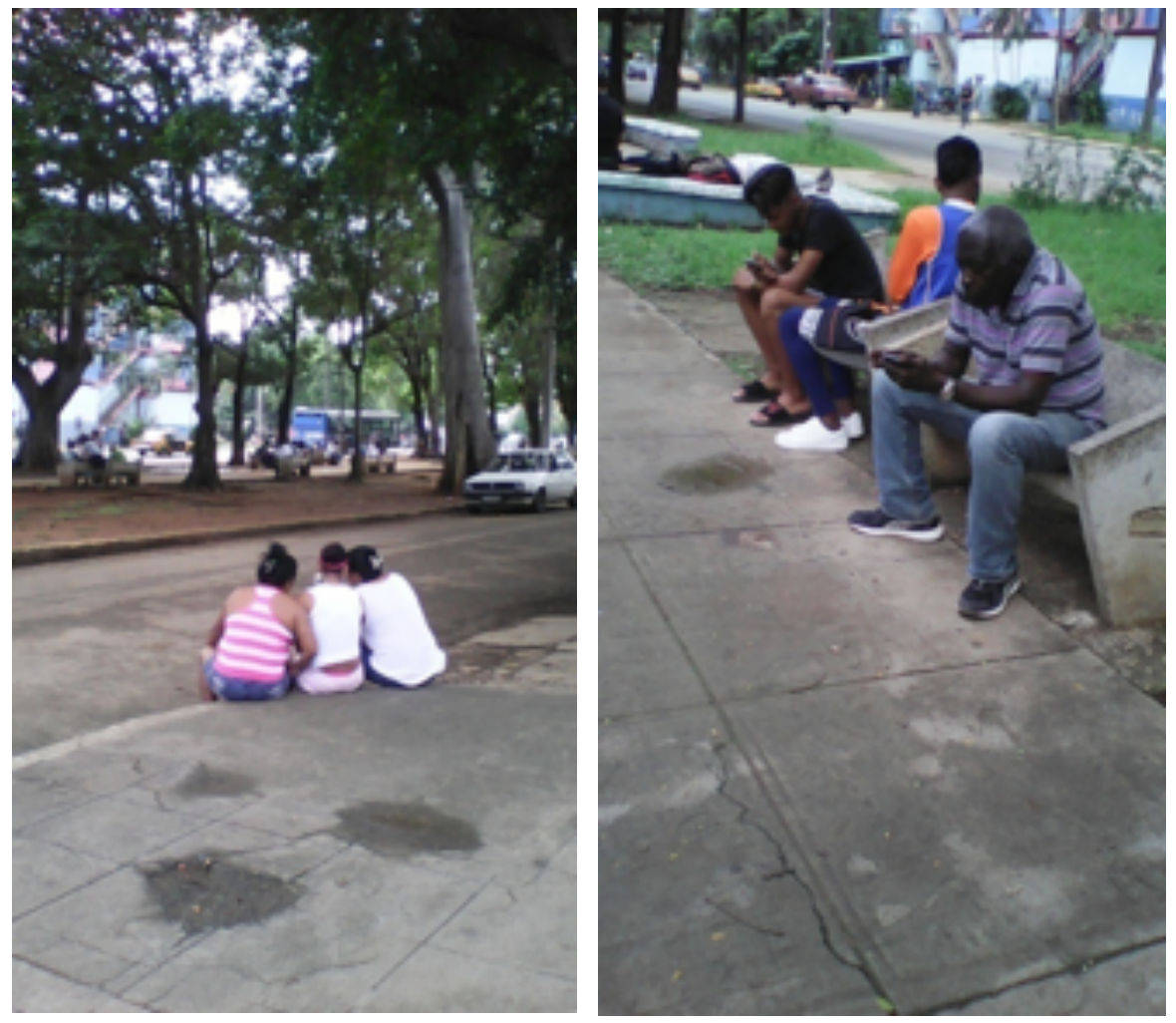


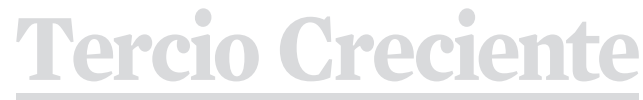

ISSN: 2340-9096

DOI: https://dx.doi.org/10.17561/rtc.n14.2

Me maquillo mi rostro, mi cabellera verde ondula libre, porto luz y me río, carajo.

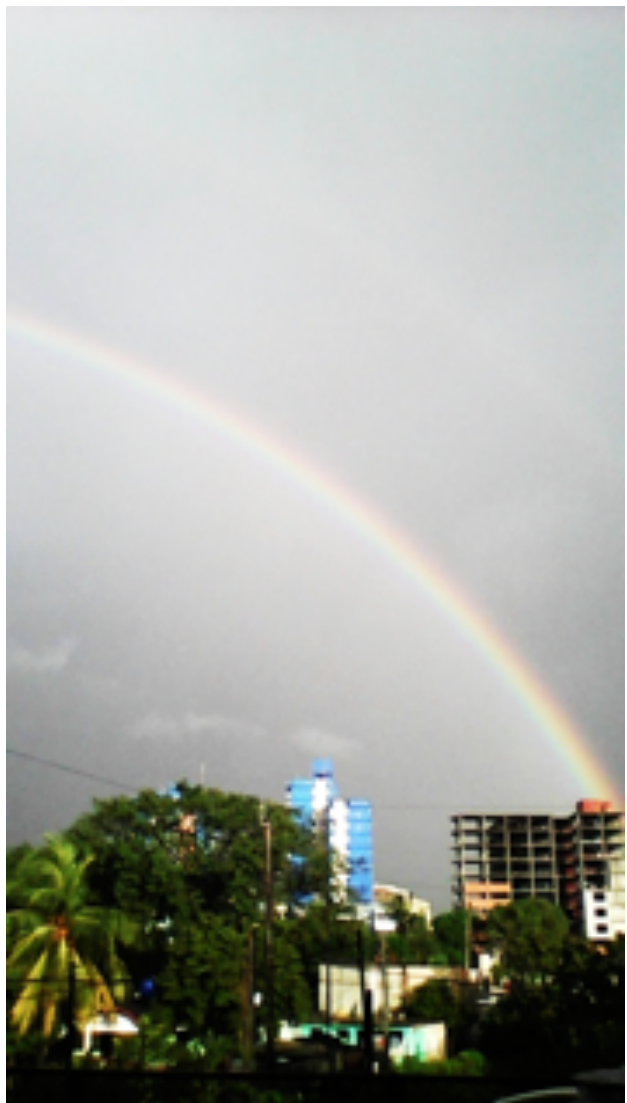




\section{Bibliografía}

Arango, G. y Pérez, C. (2007). Atrapar lo invisible. Etnografía audiovisual y ficción. Anagramas Volumen 6 núm 12 pp 129-140 Enero/junio de 2008/192 p. Medellín, Colombia.

Careri, F. (2009). Land \&Scape Series:Walkscapes. El andar como práctica estética. México: Gustavo Gili, SL.

Martínez, A. (s/f). La antropología visual. Madrid: Síntesis, S.A. PDF

Marínez, M. (2015). Andando... la acción de andar como investigación artística desde una perspectiva a/r/ tográfica. Tesis doctoral. Universidad de Jaén Didáctica de la Expresión musical Plástica y Corporal .

Pinto, C. (1998). Sociología visual. Estrategias audiovisuales en el análisis cualitativo de la realidad social. Universidad de Barcelona: 1998 by Fundación Infancia y Aprendizaje Comunicación y Cultura 1998,516,7381

Viola, B. (2005). Nota 1981 Sobre la naturaleza de las imágenes file:// DI/Ancoiglesias/TxT/Arte\%20 contemporáneo/ Sobre\% 20 la\%20naturaleza\%20 de\% 20las\%20imagenes.htm(20t2) 05/06/2005 7:51:02:am PDF.

Viola, B. (1993). Más allá de la mirada(imágenes no vistas). Museo Nacional Centro de Arte Reina Sofía. Madrid, 15 de junio al 23 de agosto 1993. PDF 